\title{
The Cognitive Economics of OTC Health: A Mind Genomics Exploration
}

\author{
Attila Gere ${ }^{1}$, Ryan Zemel ${ }^{2}$, Stephen D. Rappaport ${ }^{3}$, Petraq Papajorgij ${ }^{4}$ and Howard Moskowitz ${ }^{5 *}$ \\ 1Szent István University, Faculty of Food Sciences, Department of Postharvest Sciences and Sensory Evaluation, Budapest, Hungary \\ 2Limbic Reviews, Chicago, IL, USA \\ 3Stephen D. Rappaport Consulting LLC, Norwalk, CT, USA \\ 4European University of Tirana, Albania \\ 5Mind Genomics Associates, Inc., White Plains, NY, USA
}

${ }^{\star}$ Corresponding author: Amnon C. Sintov, Laboratory for Biopharmaceutics, Department of Biomedical Engineering, Ben Gurion University of the Negev, Be'er Sheva 84105, Israel; Tel: +972-8-647-2709; Email: asintov@bgu.ac.il

Received: October 04, 2019; Accepted: October 14, 2019; Published: October 23, 2019;

\begin{abstract}
Using the paradigms of Mind Genomics, consumers evaluated different combinations of brand, features, and performance of antacids, with the former elements combined into small, easy-to-read combinations (vignettes.) Each respondent rated a unique set of 63 vignettes on two attributes, interest in the product, and price that would be paid for a week supply of the product. The deconstruction of the vignettes into the contribution of components revealed large differences in the contribution of the components of the vignette to both interest and to price. The strongest performing elements dealt with the specific uses of the product. Price covered with interest, with some anomalies, the most striking being the high price assigned to a well-known expensive brand, (brand) Zantac, which did not perform well in terms of interest. Respondent thus 'know' price from their experience, and do not simply assign higher prices to elements they like. The mind-set segments were complex, showing that even with as many as four mind-sets, consumer lump together product features, and performance.
\end{abstract}

\section{Introduction}

In 2012 author HRM was asked by the new owner of one of the old-brand antacids to help understand the 'mind of the antacid user.' The objective of the researcher was to uncover both the messages to which an antacid user would respond, and to understand the cognitive economics of these messages, specifically how much was each message worth in dollars and cents. The objectives were both business and scientific. The business application was to refresh the messaging. The scientific application was to create a base of knowledge about the mind of the OTC consumer. Most of the information extant to date was either store-information from the 'trade,' or the data from a set of disconnected short reports from market researchers about the product, data that could easily be woven into a single coherent database.

The data reported here come from that study, owned in its entirety by author HRM, and thus available for publication. The importance of the paper is both substantive, revealing the mind of the consumer, and methodological, showing how to understand both what is important, and the value of that importance.

Anti-acid drugs, available on prescription by a physician, possess the potential to block gastric digestion of food allergens and consequently elevate the risk for food sensitization [1-4].

Over-The-Counter (OTC) antacids also increase the gastric $\mathrm{pH}$, in turn increasing the risk for sensitization against food allergens, even to those that are usually digestion-labile [5]. The increasing medical concern with the widespread usage of antacids world-wide may be partly correlated with the recognition of the dramatic increase in food allergies during the past decades. The broadest use of antacids is in the US. In the richer, more developed West European countries (Germany, Belgium, Italy and the UK) antacids also play a remarkable role. In Latin American countries, Mexico, Argentina, Brazil antacids are used less frequently. Furthermore, the antacids used in these Latin American countries are different brands and different formulations, versus the formulations and brands used by West Europeans [6] there are many similarities in preferences and patterns of antacids use between countries, but most antacids used are OTC, and most regular users keep a stock of them. National variations between Europeans and Americans partly explained by cultural differences that shape one's perceptions regarding symptoms affecting their treatment needs, preferences and expectations [7].

In contrast to Europeans, Americans consume several brands that they freely obtain from drug stores reflecting a broad OTC market but. Furthermore, in the US antacids are used not only as a treatment for symptoms of gastro-esophageal reflux but for other disease with similar symptoms [8] The widespread use of antacids is not limited to those who report occasional heartburn, but rather antacids are used widely for other issues that the patient self-treats [9].

Furthermore, antacids have become the most commonly prescribed medication for patients with ISB (irritable bowel syndrome), rather 
than for the original use to treat reflux disease [10]. This popularity of antacids may be explained by patients' expectations for a treatment to provide a quick, long lasting relief. As a consequence, the use of antacids may be expected to increase in the future because it drives patient satisfaction, may improve clinical outcomes, together the components for a useful medical intervention [11].

Studies on patient expectations from antacids and proper communication regarding their safe use are scarce. The ongoing, indiscriminate use of antacids for a broad range of abdominal diseases, increase the gastric $\mathrm{pH}$ and the risk for sensitization to food allergens. It is relevant at the psychological level to understand how people perceive antacids, what they expect from treatment with antacids and to what extent they are aware of long- term risks of its wide use for diseases other than gastro-esophageal, acid reflux.

This study focuses on mapping patient perceptions and expectations, uncover general trends for the total population, and searching for mind-set segments, different groups of individuals who perceive the use and benefit of antacids in different ways. The study is part of the effort of Mind Genomics, an emerging science, to drive better medical outcomes by understanding the 'mind of the patient' and the 'mind of the health professional', in order to create better communications by the health professionals, and better outcomes for the patient.

\section{Method}

The approach we used is known by the rubric of Mind Genomics. Simply stated, Mind Genomics quantifies ideas on different dimensions, and uncovers new-to-the-world minds-sets of people, groups of individuals who are similar in the pattern of responses to the particular stimulus. The methods of Mind Genomics derive from the statistical discipline of experimental design [12], wherein the independent variables are complete messages of ideas. Applications of Mind Genomics have ranged from food to drugs to jewelry, and so forth [13].

Mind Genomics began as a topic in mathematical psychology, 'Conjoint Measurement' [14] The approach, experimental design of ideas, found ready interest in marketing, led by pioneer researcher Paul Green and his colleagues at the Wharton School of Business of the University of Pennsylvania $[15,16]$. The underlying science of conjoint measurement has thus almost a 60- year history, but it is during the past 25 years, that the approach has found wide use in applications, perhaps because the method migrated from a custom set up to an ad hoc, DIY (do-it-yourself) system [17,18].

Mind Genomics follows these steps to uncover what motivates people.

1. Identify questions and their answers. The metaphor of questions and answers makes the task easier for those who are just beginning to explore the mind of people in this manner. People find asking questions to be easy. It is the specific questions which are hard. Once the questions are framed, it becomes easy to formulate answers. This study used seven questions, each with five answers (a so-called 7x5 design). The questions (and answers) appear in Table 1.
2. The questions tell the story. The answers provide the detail. It is the combination of answers from different questions which become the vignettes that the respondents will rate in the actual evaluation. As Table 1 shows, the answers are not specific permutations of the question, but rather different 'snapshots.' The questions become simply the means by which to elicit the answers in the preparatory portion of the research, ahead of the actual evaluations. The respondents never see the questions, but rather only see the answers.

3. The specific choice of questions and answers addressed dual. The first objective was to understand the decision criteria of people regarding antacids. This was the scientific criterion. The second objective was to use these data to help reposition one of the antacids for the commercial market. The second objective, repositioning the antacid, required us to study brand as the first question, although the actual position of the brand name in the test vignettes (combinations of answers) could have been in any one of the different positions.

4. The answers are combined by experimental design into vignettes, combinations comprising 2-4 answers. Each answer appeared six times across the 63 vignettes and was absent 57 times. The experimental design thus creates incomplete vignettes. Although some practitioners using experimental design insist on having each vignette complete, with one answer from each of the seven questions, that approach is rife with problems, such as multicollinearity (lack of independence of the answers as predictor variables in regression), and the sheer difficulty of reading 63 vignettes of seven elements each. The strategy used here ensures statistical independence, and reduces the onerousness of the task, an important consideration in this type of research.

5. The respondents rated each vignette twice, first on interest, and second on price that they would pay. We selected five price points and presented them in the same irregular order. The decision to present the prices in irregular order was based on the desire to make sure that there was no similar pattern in answers to the two rating scales, so that a respondent interested in a product description would ordinary select a higher price. The presentation in irregular order removes that possible bias.

6. Figure 1 shows an example of a vignette comprising three answers, and the rating on the bottom for the first question. The same vignette was presented, but the question changed, this time instructing the respondent to select a price.

7. The respondents were run with a panel company (Turk Prime, Inc.), specializing in on-line panels of this type. The respondents are already members of the panel, for which they receive incentives, distributed by the panel company. Figure 2 shows the orientation page sent to those respondents who agreed to participate. The orientation itself gives little information about the topic of the study, other than it deals with an antacid treatment. The rest of the orientation focuses on the time for the interview, the two questions, and the instruction to consider the entire screen (the full vignette) as one idea. 
Table 1. The seven questions and the five answers/question.

\begin{tabular}{|c|c|}
\hline & What is the brand name of the product? \\
\hline A1 & (brand) Zantac \\
\hline A2 & (brand) Tums \\
\hline A3 & (brand) Briosche \\
\hline A4 & (brand) Alka-Seltzer \\
\hline \multirow[t]{2}{*}{ A5 } & (brand) Mylanta \\
\hline & What is the form of the product? \\
\hline B1 & In pill form \\
\hline B2 & In liquid form \\
\hline B3 & In chewable tablets \\
\hline B4 & In fizzy tablets \\
\hline \multirow[t]{2}{*}{ B5 } & In capsules \\
\hline & What is unusual and/or special about the product? \\
\hline $\mathrm{C} 1$ & Faster ... more complete absorption of this effervescent antacid versus conventional tablets \\
\hline $\mathrm{C} 2$ & All natural and aspirin free ... It's simply a great product! \\
\hline $\mathrm{C} 3$ & Some antacids contain aluminum hydroxide or calcium carbonate, which can cause constipation ... NOT US! \\
\hline $\mathrm{C} 4$ & For over 125 years we provided heartburn treatment the world over \\
\hline \multirow[t]{2}{*}{ C5 } & Though over-the-counter antacids are considered safe \& effective ... not all antacids are for every "body" \\
\hline & How does the product taste? \\
\hline D1 & No taste betrays the fact that this is an antacid \\
\hline D2 & Available in three great tasting flavors: Smooth Lemon Creme, Smooth Mint Creme, and Smooth Cherry Crème" \\
\hline D3 & Tastes like a milk shake! \\
\hline D4 & Does not taste "pasty or chalky" like most popular antacids \\
\hline \multirow[t]{2}{*}{ D5 } & With its crisp, clean lemon taste, it's a pleasure to take to relieve your symptoms! \\
\hline & How does it relieve your heartburn, and how then do you feel? \\
\hline E1 & Relieves your heartburn, acid indigestion, and upset stomach without unnecessary chemicals, ingredients, or preservatives \\
\hline E2 & Has $600 \mathrm{mg}$ of calcium in each dose, which helps to treat osteoporosis ... two benefits in one! \\
\hline E3 & Enjoy all of your favorite foods without the threat of heartburn holding you back \\
\hline E4 & Starts to work instantly \\
\hline \multirow[t]{2}{*}{ E5 } & It's also great in relieving nausea, and helps with a hangover too \\
\hline & How do you get it and use it? \\
\hline F1 & Just pour a capful (or a foil pack) into $4 \mathrm{oz}$ of water and within 10 seconds relief is on its way! \\
\hline F2 & This antacid is available through most retail drug stores, food stores, or mass merchandisers \\
\hline F3 & The expiration date on our product is for 5 years! \\
\hline F4 & With 12 child friendly handy dandy foils ... makes sure your child has relief close by whether they are at home, going to a friend's or throwing an awesome birthday party! \\
\hline \multirow[t]{2}{*}{ F5 } & Dissolves in your mouth ... you don't need water to swallow it \\
\hline & Who uses it, and for what? \\
\hline G1 & Antacids can provide fast, safe relief for your pregnancy heartburn \\
\hline G2 & Antacids are frequently given to babies to reduce the acidity of stomach contents which are refluxed into the food pipe \\
\hline G3 & The same medication in different forms ... for people who need to have different methods to choose from \\
\hline G4 & For people with occasional, mild to moderate symptoms of heartburn, antacids are often all that is needed to control the symptoms \\
\hline G5 & Pain, gas, indigestion ... relieve the symptoms and recover from overeating by taking an over-the-counter antacid \\
\hline
\end{tabular}




\section{Zantac}

Faster ... more complete absorption of this effervescent antacid versus conventional tablets

Starts to work instantly

How interested are you in buying this Antacid treatment based on this information?

\section{\begin{tabular}{|l|l|l|l|l|l|l|l|l|}
\hline 1 & 2 & 3 & 4 & 5 & 6 & 7 & 8 & 9
\end{tabular}}

$1=$ Not at all interested $\ldots 9=$ Extremely interested

Figure 1. Example of three-answer vignette and the rating scale on the bottom for Question \#1 (interest).

\section{Today, you will be taking a survey regarding an Antacid treatment}

What people are looking for when choosing an Antacid?

We will ask you to help us find out!

It will take you between $10-15$ minutes to complete this survey

You will be seeing different screens describing various aspects of this product

You will be asked two questions for each screen description of combinations:

1) How interested are you in buying this Antacid treatment based on this information?

$<-$ Not at all interested

1

23
Extremely interested - ->

4

5

6

7

8

9

2) Based on this screen ALONE... How much would you pay for a weekly supply of an Antacid?

$1=\$ 1.992=\$ 5.993=\$ 3.99 \quad 4=\$ 9.995=\$ 7.99$

You will rate he SAME 2 questions for each screen

Please rate each screen combination as a single unit

You can track your progress on the top right of each screen

Thank you very much for your participation in this important survey

Please Click $\gg$ to Continue

$>$

Figure 2. The orientation page shown to the respondent at the start of the web-based experiment. 
8. At the end of the respondent's evaluation of the 63 vignettes on the two rating questions, the respondent completed a detailed self-profiling classification, which instructed the respondent to profile WHO the respondent is, WHAT the respondent believes to be important in an antacid, what BEHAVIORS the respondent follows when taking an antacid (e.g., frequency), and finally, and from what MEDICAL conditions relevant to an antacid does the respondent suffer. This information provides the means by which to analyze the results provided by different, pre-defined groups of respondents. We focus our analysis on total panel, on gender (showing little difference), and on mind-set segment (showing far more differences.)

\section{Creating the Data for Analysis}

We follow a specific pattern of data analysis, one laid down over 35 years of research. The objective of the analysis is to use OLS (ordinary least-squares) regression to deconstruct the ratings into the contribution of the individual answers, i.e., the 35 elements. In the OLS regression, the 35 elements will become the independent variables, and the ratings, or more correctly the transformed ratings, will become the dependent variables.

We follow these steps:

1. Transform the ratings from Question \#1 (interest in buying) from a 9-point scale to a 2-point scale. Ratings of 1-6 are transformed to 0 . Ratings of 7-9 are transformed to 100 . A small random number $\left(<10^{-5}\right)$ is added to the newly created binary values in order to create some small variation in the transformed ratings, so that the regression modeling does not crash. The transformation moves us from the consideration of responses as 'degree of interest' to no/ yes, might or might not buy, would not buy (ratings 1-6), or would buy (ratings 7-9). The transformation is done in the interest of interpretability, because the reality is that it is easier to understand the meaning of no/yes than to understand the meaning of a scale value.

2. Transform the selection of prices from Question \#2 to the actual dollar value specified by the questionnaire. Again, add a very small random number $\left(<10^{-5}\right)$ to ensure that the regression model does not crash in those cases when the respondent selects the same price for all vignettes evaluated.

3. Considering the data from Question \#1 (interest), run a simple OLS regression model relating the presence/absence of the 35 elements to the binary ratings. The regression model is run at the level of the individual respondent, after the ratings have been transformed. The corresponding coefficients are averaged across all the relevant respondents in the subgroup. The equation is written as follows:

Binary Rating (Question \#1) $=\mathrm{k}_{0}+\mathrm{k}_{1}(\mathrm{~A} 1)+\mathrm{k}_{2}(\mathrm{~A} 2) \ldots \mathrm{k}_{35}(\mathrm{G} 5)$

4. Following the above-described approach and considering the data from Question \#2 (price in dollars and cents), run a second, simple OLS regression relating the presence/absence of the 35 elements to the price paid. The equation does not have an additive constant, because of the ingoing assumption that no one would pay any money without knowing about the product. The equation is written as follows:
Price Selection (Question \#2) $=\mathrm{k}_{1}(\mathrm{~A} 1)+\mathrm{k}_{2}(\mathrm{~A} 2) \ldots \mathrm{k}_{35}(\mathrm{G} 5)$

\section{Results - Total Panel}

Table 2 shows the summary statistics from the total panel.

The basic interest in the product is 13 . This means that without any additional information about the antacid, only about $13 \%$ of the respondents would assign a rating of 7-9, a strong positive rating for interest. It is the answers, the elements of the vignette, which must do the work. By itself, the antacid is not of much interest, at least to the total panel.

The strongest elements or answers to questions for the respondents are those which talk about 'relief' or 'treatment.' It is the concrete claim which is convincing. These three are the following:

It's also great in relieving nausea, and helps with a hangover too

Has $600 \mathrm{mg}$ of calcium in each dose, which helps to treat osteoporosis ... two benefits in one!

Relieves your heartburn, acid indigestion, and upset stomach without unnecessary chemicals, ingredients, or preservatives

There is a generally positive relation between the price one is willing to pay and the interest in the feature. Table 2 shows these partworth dollar values. Figure 3 shows the scatterplot for the 35 answers, with the abscissa showing the interest in the element, and the ordinate showing the price that one is willing to pay. The OLS regression enables us to deconstruct the price into the part-worth contributions of the 35 answers or elements, just as OLS regression enabled us to deconstruct the binary rating into the part-worth contributions. As we saw for the interest coefficients, the highest prices are associated with the direct benefits from usage (relieve nausea, treats osteoporosis, relieves heartburn.) There is one more high price, that associated with brand (brand) Zantac, not so much because of the interest in brand (brand) Zantac, but more likely because of the generally higher price one pays for brand (brand) Zantac.

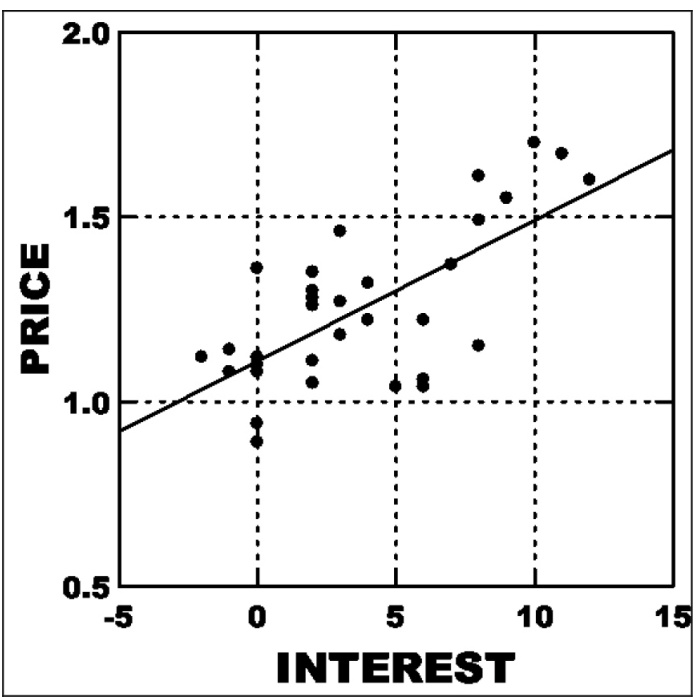

Figure 3. Scatterplot showing the relation between the coefficient for the price model (ordinate) and the corresponding coefficient for the interest mode (abscissa). The equation is: Price $=1.106+0.04$ (Interest). The correlation is 0.67 . 
Table 2. Coefficients for the additive models showing the contribution to interest and to price, respectively.

\begin{tabular}{|c|c|c|c|}
\hline & Total Panel $(\mathrm{n}=\mathbf{2 0 1})$ & INT & Price \\
\hline & Additive constant & 13 & \\
\hline E5 & It's also great in relieving nausea, and helps with a hangover too & 12 & 1.60 \\
\hline E2 & Has $600 \mathrm{mg}$ of calcium in each dose, which helps to treat osteoporosis ... two benefits in one! & 11 & 1.67 \\
\hline E1 & Relieves your heartburn, acid indigestion, and upset stomach without unnecessary chemicals, ingredients, or preservatives & 10 & 1.70 \\
\hline D2 & Available in three great tasting flavors: Smooth Lemon Creme, Smooth Mint Creme, and Smooth Cherry Crème" & 9 & 1.55 \\
\hline E4 & Starts to work instantly & 9 & 1.55 \\
\hline D3 & Tastes like a milk shake! & 8 & 1.49 \\
\hline G5 & Pain, gas, indigestion ... relieve the symptoms and recover from overeating by taking an over-the-counter antacid & 8 & 1.15 \\
\hline A1 & (brand) Zantac & 8 & 1.61 \\
\hline E3 & Enjoy all of your favorite foods without the threat of heartburn holding you back & 7 & 1.37 \\
\hline G4 & For people with occasional, mild to moderate symptoms of heartburn, antacids are often all that is needed to control the symptoms & 6 & 1.22 \\
\hline G1 & Antacids can provide fast, safe relief for your pregnancy heartburn & 6 & 1.06 \\
\hline A2 & (brand) Tums & 6 & 1.04 \\
\hline B3 & In chewable tablets & 6 & 1.06 \\
\hline G3 & The same medication in different forms ... for people who need to have different methods to choose from & 5 & 1.04 \\
\hline B5 & In capsules & 4 & 1.22 \\
\hline $\mathrm{C} 4$ & For over 125 years we provided heartburn treatment the world over & 4 & 1.32 \\
\hline D5 & With its crisp, clean lemon taste, it's a pleasure to take to relieve your symptoms! & 3 & 1.27 \\
\hline B1 & In pill form & 3 & 1.18 \\
\hline $\mathrm{C} 2$ & All natural and aspirin free ... It's simply a great product! & 3 & 1.46 \\
\hline F1 & Just pour a capful (or a foil pack) into $4 \mathrm{oz}$ of water and within 10 seconds relief is on its way! & 2 & 1.35 \\
\hline $\mathrm{C} 1$ & Faster ... more complete absorption of this effervescent antacid versus conventional tablets & 2 & 1.35 \\
\hline $\mathrm{F} 2$ & This antacid is available through most retail drug stores, food stores, or mass merchandisers & 2 & 1.11 \\
\hline $\mathrm{C} 3$ & Some antacids contain aluminum hydroxide or calcium carbonate, which can cause constipation ... NOT US! & 2 & 1.28 \\
\hline G2 & Antacids are frequently given to babies to reduce the acidity of stomach contents which are refluxed into the food pipe & 2 & 1.05 \\
\hline D4 & Does not taste "pasty or chalky" like most popular antacids & 2 & 1.30 \\
\hline F5 & Dissolves in your mouth ... you don't need water to swallow it & 2 & 1.26 \\
\hline $\mathrm{B} 2$ & In liquid form & 0 & 1.12 \\
\hline D1 & No taste betrays the fact that this is an antacid & 0 & 1.08 \\
\hline A4 & (brand) Alka-Seltzer & 0 & 0.94 \\
\hline F3 & The expiration date on our product is for 5 years! & 0 & 1.36 \\
\hline B4 & In fizzy tablets & 0 & 0.89 \\
\hline $\mathrm{C} 5$ & Though over-the-counter antacids are considered safe \& effective ... not all antacids are for every "body" & 0 & 1.10 \\
\hline A3 & (brand) Briosche & -1 & 1.08 \\
\hline A5 & (brand) Mylanta & -1 & 1.14 \\
\hline F4 & $\begin{array}{l}\text { With } 12 \text { child friendly handy dandy foils ... makes sure your child has relief close by whether they are at home, going to a friend's or } \\
\text { throwing an awesome birthday party! }\end{array}$ & -2 & 1.12 \\
\hline
\end{tabular}




\section{Gender Differences are Minor}

One of the first questions asked by researchers is whether there are gender differences. With around 100 respondents of each gender, we can answer that question easily for the case of antacids. Table 3 shows that the additive constant is slightly higher for females than for males (16 versus 9), but both are very low. For the most part, the coefficients are similar; except for a large difference in element E2 (Has $600 \mathrm{mg}$ of calcium in each dose, which helps to treat osteoporosis ... two benefits in one!). Osteoporosis affects women far more than it affects men. The coefficient for this element among women is the highest (coefficient $=15)$.

Table 3. Comparing male and female coefficients for the strongest performing elements.

\begin{tabular}{|c|c|c|c|c|}
\hline & & Total & Male & Female \\
\hline & Base Size & 201 & 88 & 113 \\
\hline & Additive constant & 13 & 9 & 16 \\
\hline E5 & $\begin{array}{l}\text { It's also great in relieving nausea, and } \\
\text { helps with a hangover too }\end{array}$ & 12 & 9 & 14 \\
\hline E2 & $\begin{array}{l}\text { Has } 600 \mathrm{mg} \text { of calcium in each dose, } \\
\text { which helps to treat osteoporosis ... two } \\
\text { benefits in one! }\end{array}$ & 11 & 5 & 15 \\
\hline E1 & $\begin{array}{l}\text { Relieves your heartburn, acid indiges- } \\
\text { tion, and upset stomach without unnec- } \\
\text { essary chemicals, ingredients, or preser- } \\
\text { vatives }\end{array}$ & 10 & 12 & 10 \\
\hline D2 & $\begin{array}{l}\text { Available in three great tasting flavors: } \\
\text { Smooth Lemon Creme, Smooth Mint } \\
\text { Creme, and Smooth Cherry Crème" }\end{array}$ & 9 & 9 & 10 \\
\hline D3 & Tastes like a milk shake! & 9 & 10 & 8 \\
\hline E4 & Starts to work instantly & 9 & 9 & 8 \\
\hline G5 & $\begin{array}{l}\text { Pain, gas, indigestion ... relieve the } \\
\text { symptoms and recover from overeating } \\
\text { by taking an over-the-counter antacid }\end{array}$ & 8 & 8 & 8 \\
\hline A1 & (brand) Zantac & 8 & 7 & 8 \\
\hline G4 & $\begin{array}{l}\text { For people with occasional, mild to } \\
\text { moderate symptoms of heartburn, antac- } \\
\text { ids are often all that is needed to control } \\
\text { the symptoms }\end{array}$ & 6 & 8 & 5 \\
\hline
\end{tabular}

\section{Mind-Sets}

One of the fundamental features of Mind Genomics is its establishment of so-called mind-sets, i.e., groups of ideas which naturally move together. These mind-sets are discovered by clustering together respondents based upon the pattern of their coefficients, in this case the 35 coefficients from the models created when we relate the presence/absence of the 35 elements to the rating of interest.

The method used to identify these mind-sets comes from the category of approaches known as cluster analysis [19]. Clustering is a well-accepted general approach to finding similar-behaving groups of objects, in our case similar-behaving groups of ideas or people. We use clustering, combining it with both people and with ideas, respectively. When we cluster the people, we are really looking for combinations of ideas which naturally move together, discovering those combinations using the people (our respondents) as the natural 'carriers of the ideas.'
The notion of dividing people by the way they think is not new. Pioneer research William Wells discussed psychographics in the early 1960 's, with psychographics turning into the clustering or division of people into like-minded groups, based upon how the way they perceive the world, and how they act in their everyday lives. Psychographics works from the general to the particular, dividing people into general groups, such as those who are 'ecology-oriented' versus others who are 'consumption oriented.' In contrast, the approach espoused here, Mind Genomics, works from the specific up to the general, taking a 'pointillist' approach. That is, for Mind Genomics, there are no general groups of people, but simply groups emerging from specific situations, and specific topics [20].

The method of k-means clustering used allows us to divide our 201 respondents into as many groups as we want, with the property that the variability within a group or cluster is relatively small (the patterns of the coefficients are similar), whereas the variability across the means of the coefficients from cluster to cluster is large (the patterns of the coefficients are different from cluster to cluster.)

Cluster analysis can extract from 2-201 clusters for our data. The objective of the analysis is to minimize the number of clusters (parsimony) while making the clusters easy to understand (interpretability.) Extracting too few clusters produces hard-tounderstand, unclear results. Extracting too many clusters creates a mountain of results which makes it hard to comprehend the underlying structure of the different mind-sets.

Table 4 shows the strongest performing elements (answers) after the extraction of two mind-sets, the most parsimonious solution emerging from cluster analysis. Only the elements with coefficients of 8 or higher are shown. It is clear from Table 4 that although the cluster analysis emerges with the most parsimonious of solutions, the interpretability of the solutions is low. There are simply too many different types of elements performing well in the emergent mindsets. One could always stretch one's definition to make sense of the disparate elements, but the objective of clustering is to simplify, not to create new groupings that are difficult to comprehend. It is the sense of 'intuitive simplicity' that is important in clustering, not the creation of new-to-the-world combinations of ideas.

We see a somewhat more reasonable result in Table 5, when we extract three clusters or mind-sets, instead of two. The mind-sets are still not quite 'crisp', comprising as they do different types of messages.

When we look at four mind-sets we see a slight 'sharpening' of the clusters, but there is still no hint that we are going to get one cluster focusing, say, on flavor, another on brand, another on usage, and so forth (see Table 6)

From our efforts to divide the respondents into different mindsets we see that in the case of antacids we have some elements or answers which emerge quickly, such as flavor and certain kinds of benefits (e.g., due to nausea.) Nonetheless, the mind-set segmentation for antacid remains puzzling, perhaps because the product combines brand, form, and function in a way that is hard to dissociate easily. Whether this continued mixing of different types of 'messages' in a cluster will continue as we continue to extract an increasing number of clusters is not relevant here. What is relevant is the discovery of a new type of product, where it appears difficult to dissociate form, function, and benefit. 
Table 4. Strong performing elements for antacids from the two-segment solution.

\begin{tabular}{|c|c|c|c|c|}
\hline & & Total & $\begin{array}{c}\text { Mind- } \\
\text { Set } 1\end{array}$ & $\begin{array}{c}\text { Mind- } \\
\text { Set } 2\end{array}$ \\
\hline & Base Size & 201 & 80 & 121 \\
\hline & Additive constant & 13 & 10 & 15 \\
\hline & Mind-Set 1 - Focus on brand & & & \\
\hline A1 & (brand) Zantac & 8 & 20 & -1 \\
\hline E5 & It's also great in relieving nausea, and helps with a hangover too & 12 & 13 & 11 \\
\hline A4 & (brand) Alka-Seltzer & 0 & 11 & -7 \\
\hline A2 & (brand) Tums & 6 & 11 & 3 \\
\hline A5 & (brand) Mylanta & -1 & 8 & -8 \\
\hline & Mind-Set 2 - Focus on flavor, and on traditional uses & & & \\
\hline D2 & Available in three great tasting flavors: Smooth Lemon Creme, Smooth Mint Creme, and Smooth Cherry Crème" & 9 & 0 & 16 \\
\hline E2 & Has $600 \mathrm{mg}$ of calcium in each dose, which helps to treat osteoporosis ... two benefits in one! & 11 & 7 & 13 \\
\hline E1 & Relieves your heartburn, acid indigestion, and upset stomach without unnecessary chemicals, ingredients, or preservatives & 10 & 6 & 13 \\
\hline D3 & Tastes like a milk shake! & 9 & 3 & 12 \\
\hline G5 & Pain, gas, indigestion ... relieve the symptoms and recover from overeating by taking an over-the-counter antacid & 8 & 3 & 11 \\
\hline G1 & Antacids can provide fast, safe relief for your pregnancy heartburn & 6 & 0 & 10 \\
\hline E4 & Starts to work instantly & 9 & 7 & 9 \\
\hline G4 & $\begin{array}{l}\text { For people with occasional, mild to moderate symptoms of heartburn, antacids are often all that is needed to control the } \\
\text { symptoms }\end{array}$ & 6 & 3 & 8 \\
\hline B3 & In chewable tablets & 6 & 2 & 8 \\
\hline G3 & The same medication in different forms ... for people who need to have different methods to choose from & 5 & 2 & 8 \\
\hline
\end{tabular}

Table 5. Strong performing elements for antacids from the three-segment solution.

\begin{tabular}{|c|c|c|c|c|c|}
\hline & & Total & $\begin{array}{c}\text { Mind- } \\
\text { Set } 1\end{array}$ & $\begin{array}{l}\text { Mind- } \\
\text { Set } 2\end{array}$ & $\begin{array}{c}\text { Mind- } \\
\text { Set } 3\end{array}$ \\
\hline & Base Size & 201 & 32 & 121 & 48 \\
\hline & Additive constant & 13 & 17 & 15 & 5 \\
\hline & Mind-Set 1 - Focus on brand, purchase, and traditional use & & & & \\
\hline A1 & (brand) Zantac & 8 & 24 & -1 & 18 \\
\hline A4 & (brand) Alka-Seltzer & 0 & 12 & -7 & 11 \\
\hline F2 & This antacid is available through most retail drug stores, food stores, or mass merchandisers & 2 & 12 & 1 & -1 \\
\hline G4 & $\begin{array}{l}\text { For people with occasional, mild to moderate symptoms of heartburn, antacids are often all that is needed to } \\
\text { control the symptoms }\end{array}$ & 6 & 9 & 8 & -1 \\
\hline \multirow[t]{2}{*}{ E2 } & Has $600 \mathrm{mg}$ of calcium in each dose, which helps to treat osteoporosis ... two benefits in one! & 11 & 8 & 13 & 6 \\
\hline & Mind-set 2 - Focus on flavor, and on traditional uses & & & & \\
\hline D2 & Available in three great tasting flavors: Smooth Lemon Creme, Smooth Mint Creme, and Smooth Cherry Crème" & 9 & -3 & 16 & 2 \\
\hline E1 & $\begin{array}{l}\text { Relieves your heartburn, acid indigestion, and upset stomach without unnecessary chemicals, ingredients, or } \\
\text { preservatives }\end{array}$ & 10 & 1 & 13 & 10 \\
\hline
\end{tabular}




\begin{tabular}{|c|c|c|c|c|c|}
\hline & & Total & $\begin{array}{l}\text { Mind- } \\
\text { Set } 1\end{array}$ & $\begin{array}{l}\text { Mind- } \\
\text { Set } 2\end{array}$ & $\begin{array}{c}\text { Mind- } \\
\text { Set } 3\end{array}$ \\
\hline D3 & Tastes like a milk shake! & 9 & 6 & 12 & 2 \\
\hline E5 & It's also great in relieving nausea, and helps with a hangover too & 12 & 7 & 11 & 16 \\
\hline G5 & Pain, gas, indigestion ... relieve the symptoms and recover from overeating by taking an over-the-counter antacid & 8 & 5 & 11 & 2 \\
\hline G1 & Antacids can provide fast, safe relief for your pregnancy heartburn & 6 & 6 & 10 & -5 \\
\hline E4 & Starts to work instantly & 9 & 7 & 9 & 7 \\
\hline B3 & In chewable tablets & 6 & -4 & 8 & 6 \\
\hline \multirow[t]{2}{*}{ G3 } & The same medication in different forms ... for people who need to have different methods to choose from & 5 & 7 & 8 & -2 \\
\hline & Mind-Set 3 - Melange of assorted messages & & & & \\
\hline $\mathrm{C} 4$ & For over 125 years we provided heartburn treatment the world over & 4 & -4 & 2 & 14 \\
\hline A2 & (brand) Tums & 6 & 7 & 3 & 14 \\
\hline $\mathrm{C} 1$ & Faster ... more complete absorption of this effervescent antacid versus conventional tablets & 2 & -2 & -1 & 12 \\
\hline $\mathrm{C} 2$ & All natural and aspirin free ... It's simply a great product! & 3 & 0 & 1 & 11 \\
\hline A5 & (brand) Mylanta & -1 & 6 & -8 & 10 \\
\hline B2 & In liquid form & 1 & -9 & -1 & 9 \\
\hline D5 & With its crisp, clean lemon taste, it's a pleasure to take to relieve your symptoms! & 3 & -3 & 3 & 9 \\
\hline A3 & (brand) Briosche & -1 & 4 & -6 & 9 \\
\hline E3 & Enjoy all of your favorite foods without the threat of heartburn holding you back & 7 & 3 & 7 & 8 \\
\hline $\mathrm{C} 5$ & Though over-the-counter antacids are considered safe \& effective ... not all antacids are for every "body" & 0 & -7 & -2 & 8 \\
\hline B5 & In capsules & 4 & 1 & 4 & 8 \\
\hline
\end{tabular}

Table 6. Strong performing elements for antacids from the four-segment solution.

\begin{tabular}{|c|c|c|c|c|c|c|}
\hline & & Total & $\begin{array}{l}\text { Mind- } \\
\text { Set } 1\end{array}$ & $\begin{array}{l}\text { Mind- } \\
\text { Set } 2\end{array}$ & $\begin{array}{l}\text { Mind- } \\
\text { Set } 3\end{array}$ & $\begin{array}{l}\text { Mind- } \\
\text { Set } 4\end{array}$ \\
\hline & Base Size & 201 & 32 & 72 & 48 & 49 \\
\hline & Additive constant & 13 & 17 & 13 & 5 & 18 \\
\hline & Mind-Set 1 - Focus on brand, purchase, and traditional use & & & & & \\
\hline $\mathrm{A} 1$ & (brand) Zantac & 8 & 24 & -4 & 18 & 3 \\
\hline A4 & (brand) Alka-Seltzer & 0 & 12 & -3 & 11 & -13 \\
\hline $\mathrm{F} 2$ & This antacid is available through most retail drug stores, food stores, or mass merchandisers & 2 & 12 & -2 & -1 & 5 \\
\hline G4 & $\begin{array}{l}\text { For people with occasional, mild to moderate symptoms of heartburn, antacids are often all that is } \\
\text { needed to control the symptoms }\end{array}$ & 6 & 9 & 10 & -1 & 5 \\
\hline \multirow[t]{2}{*}{ E2 } & Has $600 \mathrm{mg}$ of calcium in each dose, which helps to treat osteoporosis ... two benefits in one! & 11 & 8 & 16 & 6 & 9 \\
\hline & Mind-Set 2 - Sensory seekers, focus on issues from eating & & & & & \\
\hline D2 & $\begin{array}{l}\text { Available in three great tasting flavors: Smooth Lemon Creme, Smooth Mint Creme, and Smooth } \\
\text { Cherry Crème" }\end{array}$ & 9 & -3 & 28 & 2 & -3 \\
\hline D3 & Tastes like a milk shake! & 9 & 6 & 27 & 2 & -10 \\
\hline G5 & $\begin{array}{l}\text { Pain, gas, indigestion ... relieve the symptoms and recover from overeating by taking an over-the- } \\
\text { counter antacid }\end{array}$ & 8 & 5 & 19 & 2 & 0 \\
\hline E5 & It's also great in relieving nausea, and helps with a hangover too & 12 & 7 & 15 & 16 & 6 \\
\hline G1 & Antacids can provide fast, safe relief for your pregnancy heartburn & 6 & 6 & 14 & -5 & 5 \\
\hline
\end{tabular}




\begin{tabular}{|c|c|c|c|c|c|c|}
\hline & & Total & $\begin{array}{l}\text { Mind- } \\
\text { Set } 1\end{array}$ & $\begin{array}{l}\text { Mind- } \\
\text { Set } 2\end{array}$ & $\begin{array}{l}\text { Mind- } \\
\text { Set } 3\end{array}$ & $\begin{array}{l}\text { Mind- } \\
\text { Set } 4\end{array}$ \\
\hline D4 & Does not taste "pasty or chalky" like most popular antacids & 2 & -7 & 13 & -1 & -6 \\
\hline E1 & $\begin{array}{l}\text { Relieves your heartburn, acid indigestion, and upset stomach without unnecessary chemicals, } \\
\text { ingredients, or preservatives }\end{array}$ & 10 & 1 & 12 & 10 & 15 \\
\hline D5 & With its crisp, clean lemon taste, it's a pleasure to take to relieve your symptoms! & 3 & -3 & 10 & 9 & -9 \\
\hline $\mathrm{E} 4$ & Starts to work instantly & 9 & 7 & 10 & 7 & 9 \\
\hline E3 & Enjoy all of your favorite foods without the threat of heartburn holding you back & 7 & 3 & 10 & 8 & 4 \\
\hline \multirow[t]{2}{*}{ G3 } & $\begin{array}{l}\text { The same medication in different forms ... for people who need to have different methods to choose } \\
\text { from }\end{array}$ & 5 & 7 & 8 & -2 & 7 \\
\hline & Mind-Set 3 - Focus on brands and forms & & & & & \\
\hline $\mathrm{C} 4$ & For over 125 years we provided heartburn treatment the world over & 4 & -4 & 2 & 14 & 1 \\
\hline A2 & (brand) Tums & 6 & 7 & 0 & 14 & 7 \\
\hline $\mathrm{C} 1$ & Faster ... more complete absorption of this effervescent antacid versus conventional tablets & 2 & -2 & -1 & 12 & 0 \\
\hline $\mathrm{C} 2$ & All natural and aspirin free ... It's simply a great product! & 3 & 0 & -1 & 11 & 4 \\
\hline A5 & (brand) Mylanta & -1 & 6 & -7 & 10 & -9 \\
\hline B2 & In liquid form & 1 & -9 & 5 & 9 & -9 \\
\hline A3 & (brand) Briosche & -1 & 4 & -9 & 9 & -1 \\
\hline C5 & $\begin{array}{l}\text { Though over-the-counter antacids are considered safe \& effective ... not all antacids are for every } \\
\text { "body" }\end{array}$ & 0 & -7 & -5 & 8 & 2 \\
\hline \multirow[t]{2}{*}{ B5 } & In capsules & 4 & 1 & 3 & 8 & 5 \\
\hline & Mind-Set 4 - Miscellaneous & & & & & \\
\hline B3 & In chewable tablets & 6 & -4 & 4 & 6 & 15 \\
\hline F3 & The expiration date on our product is for 5 years! & 0 & 5 & -2 & -8 & 8 \\
\hline
\end{tabular}

\section{How Does Brand Interact with the Different Answers to Drive Price?}

The systematized permutation approach used by Mind Genomics assures that set of $63 \times 201$ vignettes $(12,663)$ cover a wide number of combinations, rather than 63 combinations repeated 201 times, once for each respondent [21]. The strategy of Mind Genomics is insight through directly measuring much of the stimulus space. The strategy of conventional research is insight by covering just a little of the stimulus space, doing so with reduced variability in the estimation through replication or through reducing external 'noise' that could affect the results.

The strategy of massively increase coverage has a benefit, namely it allows the stratification of the vignettes by brand. That is, the 12,663 vignettes can be stratified into six sets of vignettes, one set for vignettes with each brand, including a set for vignettes with no brand. The full set of respondents contributes to each stratum, so the regression analyses must be run on a group basis. That is, the power of a 'withinsubjects design' is sacrificed, but in its place is a sense of how the same elements perform in the presence of different brands.
Table 7 shows the nature of the interaction between brand and elements. The elements are sorted from high to low, based upon the price that is estimated for the element in the absence of brand. Thus, element E2 (Has $600 \mathrm{mg}$ of calcium in each dose, which helps to treat osteoporosis ... two benefits in one!) has the highest value (\$1.62), whereas the 'puffery' statement (All natural and aspirin free ... It's simply a great product!) has the lowest value (\$1.31).

What emerges from Table 7 is the fact that some elements, such as the strong performer, E2, with $600 \mathrm{mg}$ of calcium, can dramatically increase in dollar value in the presence of brands, whereas other elements such as element G2, with less cogent messages (Antacids are frequently given to babies to reduce the acidity of stomach contents which are refluxed into the food pipe) can increase price, but far less dramatically.

The results for this analysis further suggest that brands interact with messages in ways that must be measured. It is not that a specific brand name adds approximately the same amount to each element. Rather, there is a unique pattern of interactions between brand name and element, a pattern that must be empirically uncovered. 
Table 7. Scenario analysis of dollar value ascribed to each element, when the vignettes are stratified by brand. The table suggests an interaction of brand and message. The table shows cells shaded when the dollar value exceeds $\$ 2.00$.

\begin{tabular}{|c|c|c|c|c|c|c|c|}
\hline & & None & $\begin{array}{l}\text { (brand) } \\
\text { Zantac }\end{array}$ & $\begin{array}{l}\text { (brand) } \\
\text { Tums }\end{array}$ & $\begin{array}{l}\text { (brand) } \\
\text { Briosche }\end{array}$ & $\begin{array}{l}\text { (brand) } \\
\text { Alka- } \\
\text { Seltzer }\end{array}$ & $\begin{array}{l}\text { (brand) } \\
\text { Mylanta }\end{array}$ \\
\hline & & A0 & A1 & $\mathrm{A} 2$ & A3 & A4 & A5 \\
\hline E2 & Has $600 \mathrm{mg}$ of calcium in each dose, which helps to treat osteoporosis ... two benefits in one! & 1.62 & 2.03 & 1.68 & 2.45 & 2.29 & 2.12 \\
\hline E1 & $\begin{array}{l}\text { Relieves your heartburn, acid indigestion, and upset stomach without unnecessary chemicals, } \\
\text { ingredients, or preservatives }\end{array}$ & 1.57 & 1.94 & 2.16 & 2.27 & 1.69 & 1.83 \\
\hline D3 & Tastes like a milk shake! & 1.56 & 1.65 & 1.63 & 1.56 & 1.67 & 2.01 \\
\hline G4 & $\begin{array}{l}\text { For people with occasional, mild to moderate symptoms of heartburn, antacids are often all that } \\
\text { is needed to control the symptoms }\end{array}$ & 1.50 & 1.40 & 1.32 & 1.68 & 1.47 & 1.92 \\
\hline E5 & It's also great in relieving nausea, and helps with a hangover too & 1.45 & 1.99 & 1.93 & 1.90 & 1.53 & 2.05 \\
\hline F3 & The expiration date on our product is for 5 years! & 1.43 & 1.88 & 1.21 & 1.23 & 1.42 & 1.36 \\
\hline E4 & Starts to work instantly & 1.40 & 2.27 & 1.97 & 1.69 & 1.37 & 1.88 \\
\hline G5 & $\begin{array}{l}\text { Pain, gas, indigestion .... relieve the symptoms and recover from overeating by taking an over- } \\
\text { the-counter antacid }\end{array}$ & 1.36 & 1.85 & 1.09 & 1.87 & 1.75 & 1.79 \\
\hline F1 & Just pour a capful (or a foil pack) into $4 \mathrm{oz}$ of water and within 10 seconds relief is on its way! & 1.35 & 1.68 & 1.54 & 1.78 & 1.75 & 1.34 \\
\hline G2 & $\begin{array}{l}\text { Antacids are frequently given to babies to reduce the acidity of stomach contents which are } \\
\text { refluxed into the food pipe }\end{array}$ & 1.35 & 1.32 & 1.41 & 1.45 & 1.59 & 1.23 \\
\hline $\mathrm{C} 1$ & Faster ... more complete absorption of this effervescent antacid versus conventional tablets & 1.32 & 1.95 & 1.38 & 1.71 & 1.78 & 1.49 \\
\hline G1 & Antacids can provide fast, safe relief for your pregnancy heartburn & 1.32 & 1.65 & 1.30 & 1.46 & 1.72 & 1.49 \\
\hline $\mathrm{C} 2$ & All natural and aspirin free ... It's simply a great product! & 1.31 & 2.19 & 1.95 & 1.81 & 1.63 & 1.99 \\
\hline
\end{tabular}

\section{Finding Respondents in Order to Increase the Effectiveness of Messaging}

An increasingly important topic in health is to get people to comply with the prescriptions from their doctors. The problem of compliance is certainly very important in the case of prescription medicines, but it may be important as well for medicines that should be taken daily, if only as a precautionary measure. Antacids may be in the category of medicines which are for momentary symptomatic relief but may also be taken on an ongoing basis.

How does a physician or a company find the correct messages, especially for an OTC (over the counter) product that should be taken regularly? The world of today, as of this writing (spring, 2019) is individual targeting, individual messaging. The mind-sets emerging from this study represent different ways of responding to the messages about antacid.

Author Gere has developed a PVI, personal viewpoint identifier, by which a person can be assigned to one of a set of mind-sets, by answering six questions. Figure 3 shows the PVI for Mind-Sets 1,2, and 3 in Table 6. Mind-Set 4 is not relevant. The focus is on assigning a person to the most likely of these three mind-sets. As of this writing (June, 2019) the PVI for this study can be found at this website: http://162.243.165.37:3838/TT39/

\section{Discussion and Conclusion}

In previous years marketers have looked at the world of OTC in terms of how to communicate the product to the world of consumers. The introduction of market segmentation using psychographics pushed the world of OTC marketing towards consumer claims, but at the same time claims having a 'shade' of medical efficacy. Indeed, efficacy claims for OTC are regulated, and the marketer is limited to what can be said.

The combination of a fundamental consumer product with medical aspects brings with it the special problem of just what to say, so that the messages are allowable, understandable to the consumer, and convincing. In ordinary Rx medicines, the communication to the consumer need not 'convince the consumer to purchase', but rather convince the patient to comply. In OTC there is the fine line between convincing to purchase and convincing to use properly.

Mind Genomics as presented in this paper provides a wealth of information about what works in terms of messaging to convince. The ability to mix brands with messages about the product and about how the product works produces a realistic set of vignettes of the type that might be encountered in the 'real world.' The knowledge emerging from the mind-set segmentation shows how to find the most appropriate messaging, solving some of the marketing issues. 


\begin{tabular}{|c|c|c|}
\hline \multicolumn{3}{|c|}{$\begin{array}{l}\text { Welcome to Shiny Typing Tool of study: } \\
\text { Brand, performance, sensory attributes, and judged dollar value of antacids }\end{array}$} \\
\hline \multicolumn{3}{|c|}{$\begin{array}{l}\text { Your answers will help us to undestand the mind of the patients. } \\
\text { How interested are you in buying this antacid treatment based on this information? }\end{array}$} \\
\hline In liquid form & not at all intersted & extremely interested \\
\hline Available in three great tasting flavors: Smooth Lemon Creme, & not a tall intersted & extremely interested \\
\hline For over 125 years we provided heartburn treatment the world over & not at all intersted & extremely interested \\
\hline (brand) Zantac & not at all intersted & extremely interested \\
\hline Antacids can provide fast, safe relief for your pregnancy heartburn & not at all intersted & extremely interested \\
\hline Tastes like a milk shake! & not at all intersted & extremely interested \\
\hline
\end{tabular}

Figure 3. Welcome screen of the PVI presenting the six questions and the binary answer scales.

\section{Welcome to Shiny Typing Tool of study:}

Brand, performance, sensory attributes, and judged dollar value of antacids

Your answers will help us to undestand the mind of the patients.

How interested are you in buying this antacid treatment based on this information?

Tastes like a milk shake!

\begin{tabular}{l|l} 
not at all intersted $\quad$ extremely interested \\
\hline
\end{tabular}

(brand) Zantac

\begin{tabular}{l|l} 
not at all intersted & extremely interested
\end{tabular}

For over 125 years we provided

heartburn treatment the world over

\begin{tabular}{l|l} 
not at all intersted & extremely interested
\end{tabular}

In liquid form

\begin{tabular}{l|l}
\hline not at all intersted & extremely interested
\end{tabular}

Antacids can provide fast, safe relief for

\begin{tabular}{l|l} 
not at all intersted $\quad$ extremely interested \\
\hline
\end{tabular} your pregnancy heartburn

Available in three great tasting flavors:

Smooth Lemon Creme, Smooth Mint

\begin{tabular}{l|l} 
not at all intersted & extremely interested
\end{tabular}

Creme, and Smooth Cherry Creme

Please provide your

email address.

We will not share your e-mail address with third-parties and it will not be used for marketing purposes.

Submit

Figure 4. Feedback screens of the PVI. Each mind-set has its personalized feedback screen presenting the name of the mindset along with a short description. The 'say' and the avoid 'elements' appear as part of the feedback. The use of the 'brand' name as part of the feedback is optional. 


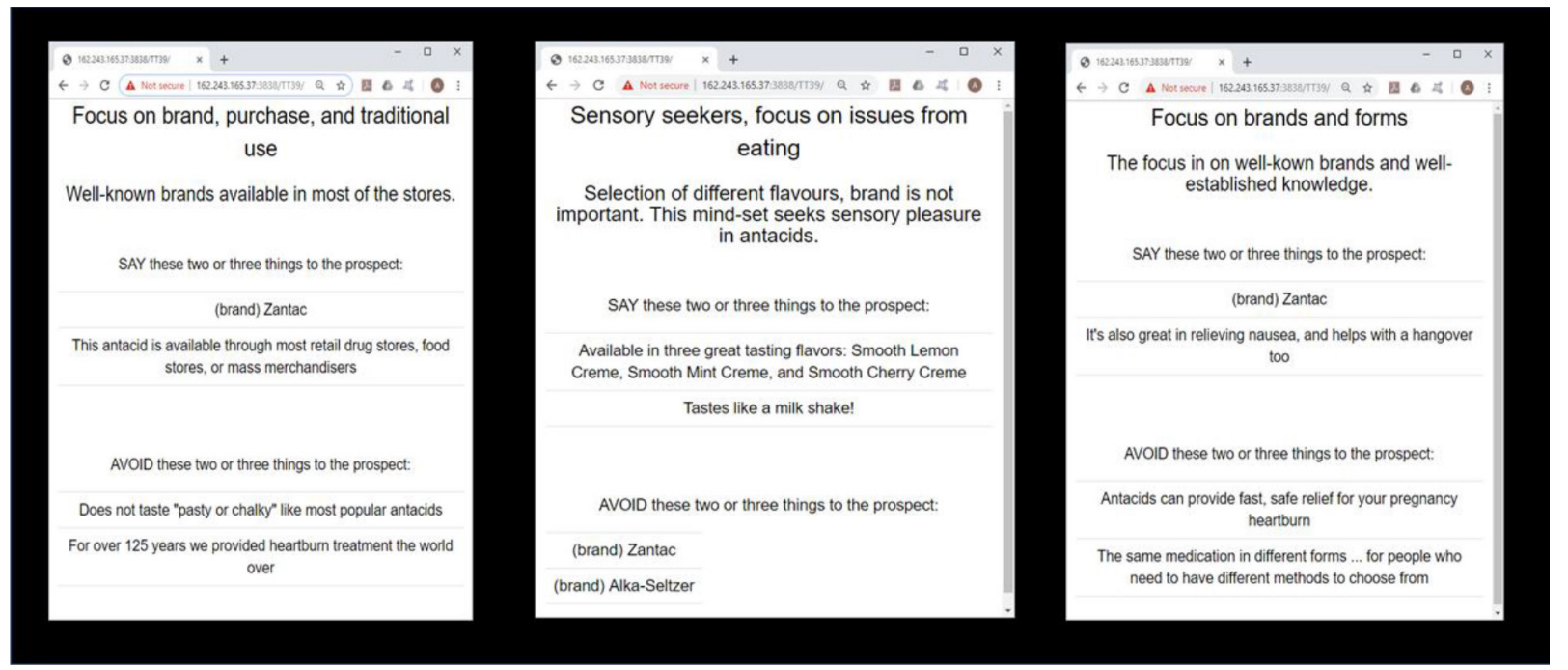

The novel introduction of price as a second component opens up a totally new area of research, 'homo economicus, economic man, and the dollar value of the messaging. The data from the total panel suggest that for the world of antacids, the interest in the product correlates quite well with the price willing to pay. These are starting data. It will be interesting to see whether we continue to see the same high correlation between interest (emotional reaction) and price (economic decision).

\section{Acknowledgement}

Attila Gere thanks the support of the Premium Postdoctoral Researcher Program of the Hungarian Academy of Sciences.

The authors would like to acknowledge the assistance of Professor Gillie Gabay, School of Behavioral Science and Psychology, College of Management, Israel.

\section{References}

1. Schöll I, Untersmayr E, Bakos N (2005) Antiulcer drugs promote oral sensitization and hypersensitivity to hazelnut allergens in BALB/c mice and humans. American Journal of Clinical Nutrition. 81: 154-160.

2. Schöll I, Ackermann U, Ozdemir C (2007) Anti-ulcer treatment during pregnancy induces food allergy in mouse mothers and a Th2-bias in their offspring. Federation of Societies of Experimental Biology Journal 21: 1264-1270.

3. Untersmayr E, Bakos N, Schöll I (2005) Anti-ulcer drugs promote IgE formation toward dietary antigens in adult patients. Federation of the Societies for Experimental Biology Journal 5: 656-858.

4. Untersmayr E, Schöll I, Swoboda I (2003) Antacid medication inhibits digestion of dietary proteins and causes food allergy: a fish allergy model in BALB/c mice. Journal of Allergy and Clinical Immunology 112: 616-623.

5. Pali-Schöll, Herzog R, Wallmann J, Szalai K, Brunner R, et al. (2010) Antacids and dietary supplements with an influence on the gastric $\mathrm{pH}$ increase the risk for food sensitization. Clinical \& Experimental Allergy 40: 1091-1098.

6. Mueller-Lissner S, Quigley EM, Helfrich I, Schaefer E (2010) Drug treatment of chronic-intermittent abdominal cramping and pain: a multi-national survey on usage and attitudes. Alimentary pharmacology \& therapeutics 32: 472-477.

7. Faresjo A, Anastasiou F, Lionis C, Johansson S, Wallander MA, Faresjo T (2006) Health-related quality of life of irritable bowel syndrome patients in different cultural settings. Health and Quality of Life Outcomes 4: 21.

8. Klauser AG, Schindlbeck NE, Mue;ler-Lissner SA (1990) Symptoms in gastrooesophageal reflux disease. Lancet 335: 205-208

9. Quigley EMM, Locke GR, Mueller-Lissner S (2006) Prevalence and management of abdominal cramping and pain: a multi-national survey. Alimentary pharmacology \& therapeutics 24 : 411-420.
10. Hungin APS, Chang L, Locke GR, Dennis EH, Barghout V (2005) Irritable bowel syndrome in the United States: prevalence, symptom patterns and impact. Alimentary pharmacology \& therapeutics 21: 1365-1475.

11. Olden K, De Garmo RG, Jhingran P (2002) Patient satisfaction with alosetron for the treatment of women with diarrhea-predominant irritable bowel syndrome. American Journal of Gastroenterology 97: 3139-3146.

12. Box GE, Hunter WG, Hunter JS (1978) Statistics for experimenters, New York, John Wiley.

13. Moskowitz HR, Gofman A (2007) Selling blue elephants: How to make great products that people want before they even know they want them. Pearson Education

14. Luce RD, Tukey JW (1964) Simultaneous conjoint measurement: A new type of fundamental measurement. Journal of mathematical psychology 1: 1-27.

15. Green PE, Rao VR (1971) Conjoint measurement for quantifying judgmental data. Journal of marketing research 8: 355-363.

16. Green PE, Srinivasan V (1990) Conjoint analysis in marketing: new developments with implications for research and practice. The journal of marketing 54: 3-19.

17. Moskowitz HR, Gofman A, Itty B, Katz R, Manchaiah M, Ma Z (2001) Rapid, inexpensive, actionable concept generation and optimization: the use and promise of self-authoring conjoint analysis. Food Service Technology 1: 149-167.

18. Moskowitz HR (2012) Mind genomics': The experimental inductive science of the ordinary, and its application to aspects of food and feeding. Physiology \& Behavior 107: 606-613.

19. Jubes R, Jain AK (1980) Clustering methodologies in exploratory data analysis. Advances in Computers 19: 113-238.

20. Wells WD (2011) Chapter 13: Life Style and Psychographics: Definitions, Uses, and Problems. In: Wells WD (ed.), Life Style and Psychographics. Marketing Classics Press, Decatur, GA, USA.

21. Gofman A, Moskowitz H (2010) Isomorphic permuted experimental designs and their application in conjoint analysis. Journal of Sensory Studies 25: 127-145.

\section{Citation:}

Gere A, Zemel R, Rappaport SD, Papajorgji P, Moskowitz H (2019) The Cognitive Economics of OTC Health: A Mind Genomics Exploration. J Pharmacol Pharm Res Volume 2 (4): 1-13. 